\title{
Chính sách người cao tuổi - Tiếp cận từ quyền cơ bản của công dân trong các hiến pháp Việt Nam
}

\section{Elderly policies - An appoarch from basic citizenship rights regulated in Vietnam's constitution}

\begin{tabular}{|c|c|}
\hline \multicolumn{2}{|c|}{$\begin{array}{l}\text { Học viện Chính trị khu vực II, Việt Nam } \\
\text { *Tác giả liên hệ, Email: buinghia72 @gmail.com }\end{array}$} \\
\hline THÔNG TIN & TÓM TẮT \\
\hline $\begin{array}{l}\text { DOI:10.46223/HCMCOUJS. } \\
\text { soci.vi.13.1.473.2018 }\end{array}$ & $\begin{array}{l}\text { Việt Nam dù đang trong thời kỳ “dân số vàng" nhưng xu } \\
\text { hướng già hóa dân số đã thành hiện thực và đang diến ra mạnh } \\
\text { mẽ. Hoạch định chính sách nhằm chủ động giải quyết với vấn đề } \\
\text { này là nhiệm vụ nặng nề của các nhà hoạch định chính sách công. }\end{array}$ \\
\hline $\begin{array}{l}\text { Ngày nhận: 11/12/2017 } \\
\text { Ngày nhận lại: 09/01/2018 }\end{array}$ & $\begin{array}{l}\text { Bài viết tập trung nghiên cứu, phân tích quy định hiến định từ } 05 \\
\text { bản Hiến pháp của Việt Nam về quyền cơ bản của công dân, } \\
\text { quyền con người - người cao tuồi; thực trạng nội dung này và }\end{array}$ \\
\hline Duyệt đăng: 15/01/2018 & $\begin{array}{l}\text { đưa ra một số khuyến nghị chính sách nhằm củng cố, hoàn thiện } \\
\text { hệ thống chính sách người cao tuổi ở nước ta thời gian tới. Thông }\end{array}$ \\
\hline $\begin{array}{l}\text { Tù khóa: } \\
\text { chính sách người cao tuổi, } \\
\text { già hóa dân số, hiến pháp } \\
\text { Việt Nam, quyền cơ bản } \\
\text { công dân }\end{array}$ & $\begin{array}{l}\text { qua phương pháp phân tích dữ liệu định tính, tổng kết thực tiễn, } \\
\text { nghiên cứu chỉ ra một cách có hệ thông những thành tựu, tồn tại } \\
\text { về chính sách người cao tuổi qua cách tiếp cận nêu trên; đồng } \\
\text { thời, chỉ ra được "khoảng chênh" giữa mục tiêu chính sách được } \\
\text { hiến định và hiện trạng thực hiện nội dung này hiện nay. }\end{array}$ \\
\hline
\end{tabular}

\begin{abstract}
Even though Vietnam's population is still in the period of "golden population structure", the country has also been experiencing a growing trend in population aging. Therefore, how to make proper policies to address this issue actively becomes a heavy task for public policymakers. This paper aims to investigate and analyze regulations of Vietnam's constitution and its five amendments on basic citizenship rights, human rights, rights for the elderly and the execution of such rights in reality, and then, based on the results, makes some policy recommendations to improve the elderly policy system in Vietnam in the coming time. Using the qualitative method to a8. 55-CV/ĐU ngày 16/03/2018 v/v Hội nghị tổng kết công tác Đảng 2017nalyze data and empirical conclusions from the reality, the
\end{abstract} Keywords:

basic citizenship rights, elderly policy, population aging, Vietnam's constitution 
paper gives a systematic look at the achievements and drawbacks of policies for the elderly through constitutional regulations on basic citizenship rights in Vietnam. The study also shows "the gap" between the target of constitutional elderly policies and the execution of related rights in reality.

\section{1. Đặt vấn đề}

Theo Qũy dân số Liên Hiệp quốc tại Việt Nam - UNFPA (2012): “Ảnh hưởng về kinh tế và xã hội của hiện tượng già hóa dân số có ý nghĩa vô cùng quan trọng, không chỉ tác động tới cá nhân người cao tuổi và gia đình họ, mà còn có tác động rộng hơn tới toàn xã hội và cộng đồng toàn cầu theo những cách thức chưa từng có".

Hiện nay, tỷ lệ người cao tuổi trên khắp thế giới đang tăng nhanh và sẽ tiếp tục tăng trong những năm tới. Theo dự báo của Liên Hiệp quốc, số người cao tuổi (từ 60 tuổi trở lên) sẽ tăng từ 760 triệu trong năm 2010 lên khoảng 2 tỷ người vào năm 2050 (tức là từ $11 \%$ lên $22 \%$ tổng dân số thế giới) (Trinh, 2016). Nếu như vào năm 1990, tỷ lệ người cao tuổi ở nước ta chỉ chiếm 7,2\% dân số thì đến năm 2011 , tỷ lệ này là $10 \%$, chính thức bắt đầu giai đoạn "già hóa dân số". Theo UNFPA dự báo, đến năm 2038, người cao tuổi ở Việt Nam sẽ chiếm $20 \%$ tổng dân số - tăng gấp ba lần trong vòng 24 năm (Qũy dân số Liên Hiệp quốc tại Việt Nam - UNFPA, 2016). Như vậy, Việt Nam sẽ đối mặt với nguy cơ "già trước khi giàu", khi tốc độ già hóa dân số tiếp tục tăng nhanh trong khi tổng sản phẩm trong nước (GDP) bình quân đầu người mới ở mức trung bình thấp (khoảng 2.000 đô la Mỹ), các chính sách an sinh xã hội, lồng ghép vấn đề chính sách này vào trong các chương trình kinh tế, chính sách y tế, ... dành cho người cao tuổi chưa thực sự hoàn chỉnh và chủ động để hướng đến đón nhận hiện tượng già hóa dân số tích cực.

Quyền được đối xử bình đẳng, được tôn trọng, chăm sóc, bảo vệ và thụ hưởng các phúc lợi trong hệ thống an sinh xã hội của người cao tuổi là đòi hỏi chính đáng và cũng là mục tiêu đặt ra cho những người xây dựng chính sách người cao tuổi. Tuy nhiên, chính sách cho người cao tuổi trong bối cảnh dân số Việt Nam đang già hóa mạnh mẽ cũng cần có những căn cứ pháp lý vững chắc, mạnh mẽ, tức là các nội dung, định hướng, giải pháp chính sách được Hiến định. Đây không chỉ là hình thức bộc lộ nội dung của chính sách người cao tuổi mà cốt lõi là phương thức, căn cứ, hiệu lực pháp lý vững chắc đảm bảo thực thi thành công mục tiêu, giải pháp giải quyết vấn đề già hóa dân số và các vấn đề phát sinh liên quan người cao tuổi ở nước ta.

Do vậy, việc nghiên cứu chính sách người cao tuổi qua góc độ tiếp cận quyền cơ bản của công dân trong Hiến pháp Việt Nam có ý nghĩa, giá trị khoa học, thực tiễn nhất định; góp phần củng cố, khẳng định mạnh mẽ tính hợp lí, hợp hiến của hệ thống chính sách người cao tuổi trong thực tiễn Việt Nam; nhận thức sâu sắc hơn về chính sách người cao tuổi qua góc độ tiếp cận mới - quyền con người, quyền công dân theo Hiến pháp và soi rọi trong thực tiễn đời sống chính sách. 
2. Cơ sở lý thuyết và mô hình nghiên cứu chính sách người cao tuổi qua cách tiếp cận về quyền cơ bản của công dân, quyền con người - người cao tuổi trong các bản Hiến pháp Việt Nam

\subsection{Chính sách công và chính sách người cao tuổi}

Chính sách công ("public policy”) là một thuật ngữ được sử dụng khá rộng rãi trong đời sống xã hội, thể hiện mối quan hệ giữa Nhà nước và công dân, xã hội trong việc xử lí các vấn đề ở tầm chính sách nhà nước. Có nhiều quan điểm của các học giả trong và ngoài nước về chính sách công, mỗi quan điểm có góc độ tiếp cận không giống nhau. Tuy nhiên, trong khuôn khổ nghiên cứu này, để là bật nổi đặc điểm cốt lõi của chính sách người cao tuổi nói riêng thì nội hàm của chính sách công được hiểu đó là: Tổng thể chương trình hành động, bao gồm mục tiêu và hệ thống giải pháp của chủ thể nắm quyền lực công nhằm giải quyết những vấn đề có tính cộng đồng trên các lĩnh vực của đời sống xã hội theo phương thức nhất định nhằm đạt mục tiêu đề ra, đảm bảo xã hội tồn tại và phát triển. Dựa trên cách thức tiếp cận này, có thể thấy, chính sách người cao tuổi Việt Nam là tổng thể chương trình hành động với những mục tiêu và hệ thống giải pháp do cơ quan nhà nước có thẩm quyền ban hành, tổ chức thực thi nhằm giải quyết các vấn đề nảy sinh liên quan đến người cao tuổi trong bối cảnh dân số quốc gia đang già hóa mạnh mẽ; từ đó, góp phần đảm bảo mục tiêu phát triển bền vững dân số và mọi mặt đời sống xã hội đất nước.

Như vậy, cấu trúc cơ bản của chính sách người cao tuổi Việt Nam sẽ bao gồm:

Một là, về hình thức biểu hiện: Trong nhà nước pháp quyền, dù muốn hay không thì các nội dung của chính sách người cao tuổi phải được biểu hiện, lồng ghép và được chuyên chở chủ yếu nhất thông qua hệ thống văn bản quy phạm pháp luật Việt Nam. Đây là cơ sở pháp lý mạnh mẽ, vững chắc cho tính hiệu lực và hiệu quả của chính sách này trên thực tế.

Hai là, về cấu trúc nội dung, gồm:

(i) Mục tiêu của chính sách người cao tuổi Việt Nam: Toàn bộ định hướng, hệ giá trị mong muốn cần đạt được và được giải quyết thông qua chính sách người cao tuổi mà các nhà hoạch định và quản lý công hướng đến. Đó có thể là mục tiêu về sự phát triển hài hòa giữa vấn đề người cao tuổi ngày càng đông đảo với việc đảm bảo sự phát triển cân đối kinh tế, xã hội,...

(ii) Hệ thống giải pháp, định hướng chính sách người cao tuổi nhằm góp phần giải quyết triệt để vấn đề liên quan người cao tuổi và già hóa dân số quốc gia;

(iii) Bộ công cụ, phương tiên cần thiết đảm bảo hỗ trợ, phục vụ đắc lực cho thực thi chính sách người cao tuổi trên thực tế.

\subsection{Chính sách người cao tuổi - Tiếp cận tù̀ quyền cơ bản của công dân, quyền con người trong các hiến pháp Việt Nam}

Như chúng ta biết, Hiến pháp là văn kiện chính trị - pháp lý quan trọng nhất trong nền lập pháp mỗi quốc gia. Trong hàng loạt nội dung được hiến định, các quy phạm pháp luật về quyền con người, quyền công dân trong hiến pháp (quyền cơ bản) gián tiếp thể hiện nội dung cốt lõi của chính sách người cao tuổi ở nước ta với các mức độ rộng, hẹp khác nhau. Vì vậy, tìm hiểu chính sách người cao tuổi thông qua tiếp cận quyền cơ bản của công dân trong các bản 
Hiến pháp Việt Nam là cách tiếp cận hợp lí, có ý nghĩa và cần thiết hiện nay. Sự ghi nhận, khẳng định hay tuyên ngôn về quyền cơ bản nói chung và trong đó có quyền dành cho người cao tuổi nói riêng sẽ vừa là hành lang pháp lí vững chắc cho việc tiếp tục hoạch định, tổ chức thực thi, thậm chí là căn cứ, tiêu chí đánh giá về toàn bộ chính sách người cao tuổi đã có theo tinh thần hiến pháp; đồng thời, đây cũng là nơi phản ánh khái quát nhất nội dung, định hướng về giải pháp, cách thức tiếp cận,... trong quá trình hoạch định chính sách người cao tuổi ở từng thời kỳ, giai đoạn phát triển khác nhau của đất nước.

Thông qua việc nghiên cứu về quy định được hiến định trong các bản Hiến pháp nước ta về quyền con người, quyền công dân - người cao tuổi, nghiên cứu này tiếp cận đối tượng nghiên cứu - quyền con người, quyền công dân là người cao tuổi tập trung vào 04 nhóm cơ bản sau đây:

(i) Quyền được cộng đồng, gia đình giúp đỡ về mặt vật chất;

(ii) Quyền được thụ hưởng hệ thống chăm sóc sức khỏe;

(iii) Quyền được đảm bảo giá trị tinh thần;

(iv) Quyền được xã hội thừa nhận, tôn trọng và khẳng định vị thế.

\subsection{Mô hình nghiên cúu, đề xuất}

Việc chỉ ra được những chuyển biến mang tính chính sách, tồn tại và hạn chế của chính sách NCT qua các bản hiến pháp ở nước ta; đồng thời, soi rọi từ quy định hiến định với thực tiễn thực hiện nội dung chính sách này là mục tiêu quan trọng của nghiên cứu. Từ khung lý thuyết nêu trên, tác giả đề xuất mô hình nghiên cứu có khái quát, cho nội dung này. Mô hình như sau:

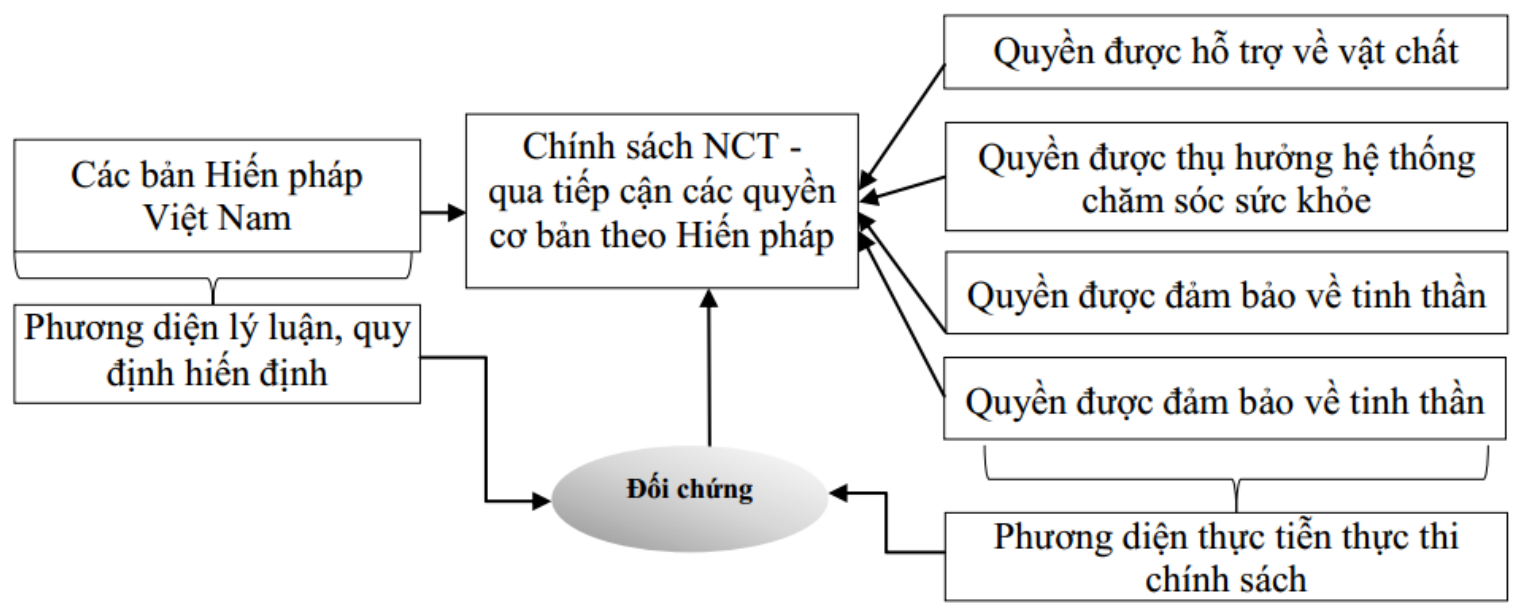

Hình 1. Mô hình nghiên cứu đề xuất

\section{Lược khảo các công trình nghiên cứu có liên quan}

Trong nghiên cứu "Chính sách chăm sóc người cao tuổi ở Việt Nam hiện nay" của GS. TS. Trịnh Duy Luận trong Tạp chí Khoa học Xã hội Việt Nam số 1(98) - 2016, tác giả tập trung đánh giá hệ thống chính sách chăm sóc người cao tuổi, nhất là khi Luật Người cao tuổi được 
Quốc hội thông qua. Nghiên cứu đã thành công khi phân tích được đánh giá khá toàn diện, đầy đủ chính sách chăm sóc người cao tuổi hiện nay thông qua các tiêu chí và từ đó đưa ra một số khuyến nghị cần thiết nhằm hoàn thiện hệ thống chính sách chăm sóc người cao tuổi. Nghiên cứu phần lớn tập trung phân tích, nghiên cứu hiện trạng chính sách người cao tuổi dựa trên phân tích một số văn bản luật, pháp quy mà chưa đề cập đến văn bản luật có tính pháp lý cao nhất Hiến pháp nhìn ở góc độ chính sách chăm sóc người cao tuổi (Trinh, 2016).

Báo cáo tổng quan về chính sách chăm sóc người già thích ứng với thay đổi cơ cấu tuổi tại Việt Nam do nhóm chuyên gia của Bộ Y tế và Quỹ dân số Liên Hiệp quốc công bố năm 2009 (Pham \& Do, 2009). Công trình đã cung cấp những cứ liệu về hiện trạng già hóa dân số toàn cầu và Việt Nam trong thế kỷ XXI, một số vấn đề đặt ra trong quá trình chăm sóc người già trước bối cảnh già hóa dân số đang trở thành vấn đề toàn cầu. Báo cáo chỉ tập trung phản ánh hiện trạng thông qua số liệu điều tra, khảo sát về hiện tượng già hóa dân số nói chung mà chưa đề cập nhiều đến hệ thống chính sách xã hội nhìn từ nội hàm của hệ thống pháp luật nước ta, trong đó tối cao là Hiến pháp. Vì vậy, đây là nền tảng để tác giả nghiên cứu, hoàn thiện nội dung bài viết này (Pham \& Do, 2009).

Đối với nghiên cứu "Luật Người cao tuổi: Thực tiễn triển khai sau 8 năm ban hành" của tác giả Nguyễn Văn Đồng đăng trên Tạp chí Xã hội học số 1(137) năm 2017. Bằng việc thu thập và phân tích dữ liệu từ một số báo cáo và các cuộc điều tra xã hội học, tác giả đã phân tích, luận giải sâu sắc về thực tiễn công tác triển khai Luật người cao tuổi sau khi ban hành; tổng kết các kết quả và kinh nghiệm sau 8 năm thực thi Luật này được ban hành (2009-2017). Bài viết là công trình nghiên cứu công phu, có giá trị và toàn diện về biểu hiện của kết quả thực thi chính sách đối với người cao tuổi Việt Nam thời gian qua nhìn từ góc độ đối chứng với Luật Người cao tuổi. Nếu tác giả mở rộng, đánh giá chủ đề này ở phạm vi tiếp cận rộng hơn và khái quát hơn ở tầm Hiến pháp sẽ tăng giá trị công trình hơn (Nguyen, 2017).

Báo cáo đề tài khoa học: Một số vấn đề cơ bản về người cao tuổi Việt Nam giai đoạn 2011 - 2020 của Viện Khoa học xã hội Việt Nam đã cung cấp bức tranh toàn diện về nhiều vấn đề cơ bản của người cao tuổi nước ta như đời sống, sức khỏe, vai trò người cao tuổi, ... và cơ sở thực tiễn điều chỉnh chính sách dành cho người cao tuổi giai đoạn 2011 - 2020. Đặc biệt, công trình đã đề cập đến một số quan điểm của Đảng và chính sách của Nhà nước về người cao tuổi, trong đó có nhắc đến một số bản Hiến pháp của nước ta. Tuy nhiên, do hạn chế về dung lượng và mục tiêu nghiên cứu của đề tài, nhóm tác giả chưa phân tích sâu sắc căn cứ pháp lí tối cao và việc hoàn thiện tư duy về chính sách chăm sóc người cao tuổi qua các bản Hiến pháp nước ta (Viện Khoa học xã hội Việt Nam, 2010).

Bài viết Tổng quan chính sách của đảng, nhà nước về người cao tuổi của Ban Thường vụ Hội Người cao tuổi Việt Nam công bố năm 2010 đã tổng kết một cách hệ thống về chủ trương của Đảng, pháp luật, chính sách của Nhà nước về người cao tuổi nước ta. Đặc biệt, tác giả cũng đã giới thiệu những nét khái quát về hệ thống luật pháp liên quan đến người cao tuổi qua các bản Hiến pháp cùng với nhiều văn bản quy phạm pháp luật khác trong suốt chiều dài lập quốc. Kết quả này bổ sung và gợi mở nhiều nội dung cho bài viết này (Viet Nam Social Work Network, 2010). 


\section{Phương pháp và dữ liệu nghiên cứu}

Nghiên cứu sử dụng phương pháp phân tích dữ liệu định tính kết hợp với phương pháp so sánh, phân tích dữ liệu định tính, ... Cụ thể:

(i) Phân tích dũ liệu định tính:

- Nghiên cứu tài liệu: Tập trung nghiên cứu các văn bản pháp lý như 05 bản Hiến pháp Việt Nam, Luật Người cao tuổi năm 2009 và một số văn bản luật, văn bản pháp quy có liên quan;

- Công trình nghiên cứu có liên quan: Dữ liệu được tác giả tiếp cận nguồn từ sách, báo, tạp chí khoa học cũng như kết quả các công trình nghiên cứu trong và ngoài nước, của các tổ chức phi chính phủ và cơ quan nhà nước nước ta (có liên quan) gồm bản in và bản điện tử như:

+ Các bài tạp chí khoa học thuộc một số tạp chí có chuyên ngành gần chủ đề như Tạp chí Xã hội học, Tạp chí Khoa học xã hội Việt Nam; Kỷ yếu hội thảo khoa học cấp tỉnh, thành phố (Viện nghiên cứu phát triển thành phố, 9/2016), hội thảo quốc tế của Trường Trung cấp Quang Trung tổ chức tại TP. Hồ Chí Minh, 8/2011; kết quả nghiên cứu một số đề tài về người cao tuổi của viện nghiên cứu chuyên ngành, Bộ Y tế, Quỹ dân số Liên Hợp quốc tại Việt Nam (UNFPA), ...

(ii) So sánh, phân tích:

Nghiên cứu tiến hành so sánh, phân tích để thấy sự đổi khác về mặt chính sách qua các bản Hiến pháp của Việt Nam; đồng thời, đánh giá kết quả thực hiện các nội dung chính sách trong các bản hiến pháp trong thực tiễn, từ đó cung cấp luận cứ lý luận, pháp lý và thực tiễn cho khuyến nghị chính sách.

\section{Kết quả nghiên cứu về Chính sách người cao tuổi qua phương diện tiếp cận về quyền cơ bản của công dân, quyền con người trong các bản hiến pháp Việt Nam}

\subsection{Hiến pháp Việt Nam năm 1946}

Người Việt Nam có truyền thống, đạo lý “kính lão, trọng thọ”. Đó là nét đẹp của người Việt ta tự ngàn xưa. Lịch sử Việt Nam cũng ghi nhận từ xa xưa đến ngày nay, từ cấp nhà nước đến cấp làng xã đều quan tâm, coi trọng người cao tuổi. Sinh thời, Chủ tịch Hồ Chí Minh rất quan tâm đến vai trò quan trọng của người cao tuổi đối với xã hội. Người nhắc nhở, trách nhiệm của các vị phụ lão chúng ta đối với nhiệm vụ đất nước thật là trọng đại. Đất nước hưng thịnh do phụ lão gây dựng, đất nước tồn tại do phụ lão giúp sức. Nước mất phụ lão cứu. Nước suy sụp phụ lão phù trì. Nước nhà hưng, suy tồn, vong, phụ lão đều gánh trách nhiệm rất nặng nề. Chính vì vậy, ngay sau khi thành lập nước, Bác Hồ cùng Chính phủ nước Việt Nam mới khẩn trương soạn thảo và ban hành Hiến pháp năm 1946 chứa đựng nhiều tư tưởng tiến bộ, nhân văn, trong đó có đề cập đến quyền của người cao tuổi. Đây vừa là căn cứ chính trị - pháp lý tối cao đầu tiên về quyền của người cao tuổi, đồng thời cũng là chính sách về người cao tuổi đầu tiên của nước ta.

Tại điều 14, Hiến pháp năm 1946 đã hiến định: "Những người công dân già cả hoặc tàn tật không làm được việc thì được giúp đỡ” (Quốc hội, 1946). Tuy quy định rất ngắn gọn trong 01 điều duy nhất, với 17 từ nhưng tư tưởng, tuyên ngôn pháp lý cao nhất đối với người cao tuổi 
có ý nghĩa đặc biệt quan trọng. Đây không chỉ là sự ghi nhận nhằm tiếp nối truyền thống, đạo lí coi trọng người cao tuổi của dân tộc Việt Nam trong văn kiện pháp lý tối cao mà sâu xa hơn, đó là sự khẳng định một cách chính thức quyền của người cao tuổi trong tổng thể hệ thống chính sách của Nhà nước, là sự cam kết trách nhiệm của nhà nước để đảm bảo quyền cơ bản cho công dân - người cao tuổi. Tuy nhiên, do là bản Hiến pháp đầu tiên, ra đời trong hoàn cảnh đất nước còn đang đối phó với thù trong, giặc ngoài nên nội dung hiến định về người cao tuổi bấy giờ chưa thực đầy đủ và toàn diện. Chẳng hạn, Hiến pháp chưa xác định rõ nội hàm "giúp đỡ" người cao tuổi là gì, hay chưa nhận thức và khái quát được mối quan hệ có tính trách nhiệm giữa một bên là nhà nước và bên còn lại (rất quan trọng) là các tổ chức còn lại trong xã hội như gia đình, xã hội, cộng đồng, ... trong việc chung tay góp sức cùng tham gia vào quá trình thực thi chính sách người cao tuổi.

\subsection{Hiến pháp Việt Nam năm 1959}

Hiến pháp năm 1959 ra đời trong hoàn cảnh cuộc kháng chiến chống Pháp của dân tộc ta thắng lợi hoàn toàn, tuy nhiên, cả nước tiếp tục đứng lên chống lại ách thống trị của đế quốc Mỹ, ngụy và thực hiện công cuộc giải phóng miền Nam thống nhất Tổ quốc. Tại Điều 32, Hiến pháp 1959 quy định: "Người lao động có quyền được giúp đỡ về vật chất khi già yếu, bệnh tật, hoặc mất sức lao động. Nhà nước mở rộng dần các tổ chức bảo hiểm xã hội, cứu tế và y tế để bảo đảm cho người lao động được hưởng quyền đảm bảo cho người lao động được hưởng quyền đó” (Quốc hội, 1959).

So với Hiến pháp 1946, nội hàm chính sách người cao tuổi dần được định hình một cách rõ ràng hơn như: đối tượng chính sách người cao tuổi - "người lao động già yếu, bệnh tật, hoặc mất sức lao động"; phương thức thực hiện chính sách - hỗ trợ vật chất; công cụ chính sách người cao tuổi đã được nhận thức, với nhiều nội dung tiến bộ như lập tổ chức bảo hiểm xã hội, cứu tế, y tế... Đây là điểm vượt trội trên cả góc độ tư duy lập pháp và tư duy chính sách đối với người cao tuổi. Qua đây, những nội dung cốt lõi của chính sách người cao tuổi trong Hiến pháp 1959 và cả giai đoạn lịch sử dân tộc (1959 - 1980) dần thể hiện rõ nét, tích cực. Tuy nhiên, so với Hiến pháp 1946, đối tượng chính sách người cao tuổi trong Hiến pháp 1959 chưa rõ - người lao động chỉ mang hàm nghĩa là người lao động tạo ra của cải vật chất phục vụ công cuộc kháng chiến kiến quốc hay thuật ngữ này cũng ám chỉ là "toàn dân”, là “công dân".

\subsection{Hiến pháp Việt Nam năm 1980}

Sau hơn 20 năm thực hiện công cuộc kháng chiến chống Mỹ cứu nước, giải phóng hoàn toàn miền Nam, thống nhất Tổ quốc, cả nước đi lên xây dựng chủ nghĩa xã hội phạm vi toàn quốc. Hiến pháp 1980 và chính sách người cao tuổi giai đoạn này ra đời trong bối cảnh đặc biệt khi đất nước đang thực hiện chế độ quản lý xã hội theo phương pháp mệnh lệnh, kế hoạch hóa tập trung, quan liêu, bao cấp toàn xã hội. Tuy nhiên, như dòng chảy xuyên suốt, Quốc hội nước ta vẫn ghi nhận, khẳng định quyền cơ bản của người cao tuổi trong tổng thể hệ thống chính sách quốc gia. Tại Điều 59, Hiến pháp 1980 nhấn mạnh: "Công nhân, viên chức khi về hưu, già yếu, bệnh tật hoặc mất sức lao động được hưởng quyền lợi bảo hiểm xã hội. Nhà nước mở rộng dần sự nghiệp bảo hiểm xã hội theo trình độ phát triển của nền kinh tế quốc dân và bảo đảm cho người lao động được hưởng quyền lợi đó" (Quốc hội, 1980). Về nội hàm chính sách người cao tuổi theo cách tiếp cận quyền cơ bản của công dân - người cao tuổi theo Hiến pháp 1980 vẫn 
kế thừa, thống nhất với các bản Hiến pháp trước đó. Tuy nhiên, có 2 điểm nổi bật dưới góc độ chính sách, cần lưu ý:

- Đối tượng thụ hưởng, thực hiện chính sách người cao tuổi có khác so với các bản Hiến pháp trước. Giai cấp công nhân, đội ngũ viên chức - trí thức xã hội - vốn là lực lượng nòng cốt cách mạng được nhắc đến nhiều hơn trong chính sách người cao tuổi giai đoạn này;

- Phương thức đảm bảo thực hiện quyền thụ hưởng lợi ích từ chính sách người cao tuổi của Nhà nước có phần thu hẹp so với các bản Hiến pháp trước đó (duy nhất chỉ được đảm bảo thông qua "bảo hiểm xã hội theo trình độ phát triển của nền kinh tế").

\subsection{Hiến pháp Việt Nam năm 1992}

Hiến pháp 1992 ra đời trong bối cảnh đất nước sau 6 năm thực hiện công cuộc đổi mới toàn diện (1986 - 1992), đẩy mạnh mở cửa, chủ động hội nhập quốc tế, sau 01 năm Đại hội Đảng toàn quốc lần thứ VII (1991) với việc thông qua Cương lĩnh xây dựng đất nước trong thời kỳ quá độ lên chủ nghĩa xã hội, ... đã trực tiếp tác động lớn đến quyền cơ bản của người cao tuổi mà cụ thể thể hiện trong chính sách người cao tuổi trong bản Hiến pháp này. Hiến pháp 1992 quy định mở rộng, chi tiết và có nhiều điểm tiến bộ về chính sách người cao tuổi so với các bản Hiến pháp trước. Tại Điều 61, quy định: "Công dân có quyền được hưởng chế độ bảo vệ sức khoẻ. Nhà nước quy định chế độ viện phí, chế độ miễn, giảm viện phí” và tại Điều 67 ghi: "Người già, người tàn tật, trẻ mồ côi không nơi nương tựa được Nhà nước và xã hội giúp đỡ" (Quốc hội, 1992). Có thể thấy, qua đây nhiều điểm tiến bộ về chính sách người cao tuổi cũng như thực thi quyền cơ bản của công dân - tư cách người cao tuổi ở nước ta giai đoạn này:

- Hiến pháp xác định rõ đối tượng thụ hưởng và tham gia thực thi chính sách người cao tuổi là "công dân". Điều này có nhiều ý nghĩa, bởi lẽ, với tư cách công dân - người cao tuổi ngoài việc được hưởng đầy đủ quyền của công dân thì quyền được thụ hưởng phúc lợi của người cao tuổi tiếp tục được đảm bảo. Điều này, Hiến pháp 1992 kế thừa tính tiến bộ, hạt nhân hợp lí từ Hiến pháp 1946;

- Điểm nổi bật nhất chính là việc Hiến pháp 1992 xác định rõ vai trò của các chủ thể có trách nhiệm trong thực hiện quyền cơ bản người cao tuổi và chính sách người cao tuổi - Nhà nước và xã hội. Việc bổ sung chủ thể "xã hội" là hợp lí với giai đoạn lúc bấy giờ và cả hiện nay. Điều này phản ánh rõ tư duy xây dựng chính sách người cao tuổi bắt đầu sát và gần hơn, phản ánh đúng với tính chất của xã hội đương đại và đồng thời tạo ra hành lang pháp lý cho nhiều tổ chức, cá nhân, pháp nhân thực tham gia thực hiện chính sách người cao tuổi ngoài sự can thiệp của nhà nước.

\subsection{Hiến pháp Việt Nam năm 2013}

Sau hơn 20 năm thực hiện Cương lĩnh xây dựng đất nước trong thời kỳ quá độ lên chủ nghĩa xã hội (1991), 10 năm thực hiện thành công Chiến lược phát triển kinh tế - xã hội giai đoạn 2001 - 2010 đã đưa nước ta ra khỏi nước nghèo, kém phát triển, Hiến pháp mới 2013 ra đời sau 3 năm thực hiện Nghị quyết Đại hội Đảng toàn quốc lần thứ XI (2011) và Cương lĩnh xây dựng đất nước trong thời kỳ quá độ lên chủ nghĩa xã hội (bổ sung, phát triển năm 2011) chứa đựng nhiều điểm tiến bộ, kế thừa được hạt nhân tiến bộ và tinh hoa trong trình độ, kỹ thuật 
và nội dung lập pháp của thế giới hiện đại. Trong bối cảnh đó, quyền cơ bản của công dân người cao tuổi và chính sách dành cho lực lượng này cũng có nhiều nội dung mới:

Một là, lần đầu tiên, quyền con người được ghi nhận trở thành quyền tối cao, được thượng tôn trong Hiến pháp, mở ra không gian pháp lý rộng lớn, điều chỉnh hết các đối tượng là người cao tuổi trong xã hội với tư cách là công dân hay chưa phải là công dân Việt Nam. Tại Điều 3 khẳng định: "Nhà nước bảo đảm và phát huy quyền làm chủ của Nhân dân; công nhận, tôn trọng, bảo vệ và bảo đảm quyền con người, quyền công dân; thực hiện mục tiêu dân giàu, nước mạnh, dân chủ, công bằng, văn minh, mọi người có cuộc sống ấm no, tự do, hạnh phúc, có điều kiện phát triển toàn diện" và tại Khoản 1, Điều 14, Hiến pháp tiếp tục nhấn mạnh: "Ở nước Cộng hòa xã hội chủ nghĩa Việt Nam, các quyền con người, quyền công dân về chính trị, dân sự, kinh tế, văn hóa, xã hội được công nhận, tôn trọng, bảo vệ, bảo đảm theo Hiến pháp và pháp luật" (Quốc hội, 2013).

Hai là, tại Khoản 3, Điều 37, Hiến pháp 2013, Quốc hội (2013) quy định rất rõ và tiến bộ về quyền công dân, quyền con người cơ bản -người cao tuổi, chính sách của Nhà nước đối với người cao tuổi: "Người cao tuổi được Nhà nước, gia đình và xã hội tôn trọng, chăm sóc và phát huy vai trò trong sự nghiệp xây dựng và bảo vệ Tổ quốc". Tại điều, khoản này đáng chú ý nhất là:

(i) Lần đầu tiên, sau hơn 75 năm lập quốc và xây dựng Hiến pháp, quyền của người cao tuổi được ghi thành một điều khoản riêng, tách hẳn với các đối tượng khác như người tàn tật, trẻ em mồ côi, ... Đây không phải là sự hiển nhiên mà khẳng định của Đảng, Nhà nước về quyền tối cao và vai trò ngày càng quan trọng của người cao tuổi trong sự nghiệp xây dựng, phát triển đất nước và vì vậy, đã đến lúc, vị trí người cao tuổi cần đúng, tương xứng với ý nghĩa vốn có của nó;

(ii) Lần đầu tiên, quyền của người cao tuổi được quy định đầy đủ nhất không chỉ được thụ hưởng giá trị vật chất, cơ bản nhất là chăm sóc sức khỏe và trọn vẹn các quyền công dân, quyền con người và đồng thời được đảm bảo các giá trị tinh thần - được tôn trọng, được công nhận, ghi nhận sự cống hiến và khẳng định vai trò của mình trong xã hội;

(iii) Lần đầu tiên, Hiến pháp quy định rất rõ tổ hợp 03 chủ thể có vai trò quan trọng trong thực hiện chính sách người cao tuổi đó là Nhà nước, gia đình, xã hội, trong đó, yếu tố "gia đình" với đầy đủ vị trí, vai trò, ý nghĩa của nó lần đầu tiên được ghi nhận;

(iv) Lần đầu tiên, Hiến pháp phản ánh đầy đủ, rõ nét tư tưởng Hồ Chí Minh về vai trò người cao tuổi trong xã hội, đặc biệt trong xã hội hiện đại. Đó là kiên quyết chống tư duy cổ xưa, lạc hậu, không hợp thời: "lão lai tài tận, lão giả an chi”, và khẳng định, người cao tuổi có vai trò quan trọng, và vai trò ấy cần có chính sách, cơ chế thu hút, phát huy, tận dụng trong sự nghiệp xây dựng và bảo vệ Tổ quốc Việt Nam hiện nay.

\subsection{Thục trạng về chính sách ngưòi cao tuổi qua cách tiếp cận về quyền con nguò̀i, quyền cơ bản của công dân trong các bản Hiến pháp Việt Nam}

Từ việc phân tích chính sách người cao tuổi qua cách tiếp cận về quyền con người, quyền cơ bản của công dân - người cao tuổi trong các bản Hiến pháp Việt Nam, tác giả tập 
trung phân tích hiện trạng của vấn đề này trên 4 nhóm quyền căn bản nhất mà người cao tuổi phải được thừa hưởng theo tinh thần Hiến pháp nước ta, cụ thể như sau:

\subsubsection{Quyền được giúp đõ về mặt vật chất}

Các bản Hiến pháp nước ta đều xuyên suốt thể hiện tư duy nhất quán: người cao tuổi cần thiết phải được hỗ trợ, giúp đỡ trước hết về mặt vật chất. Hỗ trợ này có thể là chế độ trợ cấp xã hội hằng tháng, chính sách hỗ trợ chi phí mua bảo hiểm y tế, bảo hiểm xã hội, cứu trợ, bảo trợ, ... bằng hệ thống ngân sách nhà nước hoặc nguồn tài chính khác. Tuy nhiên, do công tác này liên quan chặt chẽ và phụ thuộc vào nguồn ngân sách, tài chính nên dẫn đến một số vấn đề phát sinh. Sau hơn 08 năm thực hiện Luật Người cao tuổi và 4 năm thực hiện Hiến pháp 2013, mức độ đáp ứng các quyền kinh tế (vật chất - xã hội) của người cao tuổi ở nước ta đạt từ 50 - 60\%, gần 90\% người cao tuổi được đảm bảo nhu cầu cơ bản về ăn, mặc, ở (Trinh, 2016). Hiện nay, xem Bộ Lao động, Thương binh và Xã hội và UNFPA (2014), cả nước có khoảng 1,5 triệu người cao tuổi được hưởng chính sách bảo trợ hằng tháng chiếm đến $77 \%$ trong tổng số đối tượng được nhận trợ cấp xã hội hằng tháng; hàng nghìn người cao tuổi được hỗ trợ xóa nhà tạm, sửa chữa nâng cấp nhà ở, tổ chức chúc thọ, mừng thọ cho hơn 1 triệu người cao tuổi, thăm hỏi, động viên ốm đau cho hơn 900.000 người cao tuổi, ... (Nguyen, 2017). Đặc biệt, theo kết quả khảo sát tại đồng bằng Bắc Bộ năm 2008, có đến 73,5\% số người cao tuổi được hỏi cho rằng chính sách trợ cấp được thực hiện tốt, con số này ở Thành phố Hồ Chí Minh năm 2010 là 51,1\% (Viện Khoa học xã hội Việt Nam, 2010).Theo chính sách người cao tuổi hiện tại, việc hưởng chế độ trợ cấp xã hội hằng tháng, hoặc được nuôi dưỡng tại cơ sở bảo trợ xã hội do nhà nước quản lý chỉ dành cho người cao tuổi cô đơn, không nơi nương tựa, không có nguồn thu nhập; người cao tuổi từ 80 tuổi trở lên không có lương hưu hoặc trợ cấp bảo hiểm xã hội; người cao tuổi còn vợ hoặc chồng nhưng già yếu, không có con cháu, người thân thích, thuộc hộ nghèo... Mặc dù đạt được những kết quả khá tích cực, toàn diện về chính sách người cao tuồi thông qua đảm bảo hiện thực hóa quyền con người, quyền công dân - người cao tuổi dưới góc độ hỗ trợ vật chất. Tuy nhiên, việc đảm bảo quyền được hưởng hỗ trợ vật chất của người cao tuổi thời gian qua vẫn còn nhiều tồn tại, thách thức như sau: Một là, ở khía cạnh nào đó, với số lượng đối tượng người cao tuổi được thụ hưởng hiện tại thì hỗ trợ vật chất chưa đủ đáp ứng nhu cầu đời sống vật chất người cao tuổi. Trong bối cảnh Việt Nam đang đối mặt với vấn đề nợ công, kinh tế có phần chững lại, ... bài toán ngân sách quốc gia đang "chật vật" để phân bổ cho các lĩnh vực phát triển, trong đó có chăm lo vật chất cho người cao tuổi cũng đang đăt ra. Hai là, theo đánh giá của người cao tuổi, công tác hỗ trợ về vật chất tuy có cải thiện nhưng vẫn còn nhiều hạn chế biểu hiện ở mức độ thỏa mãn, hài lòng được thụ hưởng về chính sách trợ cấp xã hội. Do điều kiện kinh tế - xã hội đặc thù từng địa phương nên với mức trợ cấp xã hội cho người cao tuổi chỉ bằng $38 \%$ chuẩn nghèo nông thôn, $30 \%$ chuẩn nghèo độ thị giai đoạn 2016 - 2020, mức chuẩn chung hỗ trợ chỉ đáp ứng được $32,5 \%$ so với chuẩn nghèo. Kết quả nghiên cứu của Viện Khoa học Lao động và Xã hội chỉ có $27 \%$ người cao tuổi đánh giá chính sách trợ cấp xã hội vừa có giá trị vật chất, tinh thần (Nguyen, 2017); khảo sát đồng bằng Bắc bộ có đến $26,5 \%$ số người cao tuổi được hỏi đánh giá chưa tốt về thực hiện hỗ trợ vật chất, riêng tại Thành phố Hồ Chí Minh cũng khá tương đồng khi có đến 17,3\% đánh giá chính sách trợ cấp xã hội ở mức không tốt và rất kém (Viện Khoa học xã hội Việt Nam, 2010). Ba là, hạn chế về nguồn ngân sách, tài chính nói chung là thách thức trong việc thực hiện chính sách hỗ trợ vật chất đối với 
người cao tuổi. Nhiều chính sách, mô hình hay, ý nghĩa trong việc hỗ trợ vật chất cho người cao tuổi chưa được thực hiện kịp thời do thiếu kinh phí và thiếu văn bản hướng dẫn. Điều này gián tiếp phản ánh sự lúng túng, bị động của chính quyền Trung ương và chính quyền địa phương trong việc tìm ra giải pháp huy động nguồn lực, phát huy vai trò cộng đồng, xã hội trong hỗ trợ người cao tuổi. Bốn là, phạm vi người cao tuổi được hưởng chính sách hỗ trợ còn ít, cần được xem xét một cách khoa học để mở rộng. Theo đánh giá của Bộ Lao động -Thương binh và $X a ̃$ hội thì diện đối tượng được hưởng trợ cấp xã hội cả nước còn thấp, đối tượng thường xuyên chỉ chiếm 1,23\% dân số (trong khi các nước khu vực là 2,5 -3,0\%). Thay vì đối tượng hưởng chính sách trợ cấp là một số nhóm người cao tuổi đặc thù (nghèo, không nơi nương tựa, cô đơn, không thu nhập, ...) cần xem xét, mở rộng ra là toàn bộ người cao tuổi (Bộ Lao động Thương binh và Xã hội, 2009).

\subsubsection{Quyền được thu hưởng chế độ chăm sóc sức khỏe}

Trong những năm qua, việc đảm bảo quyền được thụ hưởng chính sách chăm sóc sức khỏe cho người cao tuổi theo Hiến pháp và pháp luật bước đầu được thưc hiện có kết quả tích cực. Tuổi thọ dân số Việt Nam tăng lên phản ánh thành tựu kinh tế - xã hội, nhất là lĩnh vực y tế. Tuy nhiên, theo Nguyen (2017), điều kiện sống, mức sống đa phần người cao tuổi nước ta còn khá thấp, sức khỏe kém, tuổi thọ khỏe mạnh nước ta chưa cao, mỗi người cao tuổi chịu 14 năm bệnh tật, $95 \%$ người cao tuổi có bệnh và trung bình là 2,69 căn bệnh/người.... Từ năm 2009 đến nay, các chương trình khám chữa bệnh đã tư vấn các bệnh về mắt cho hơn 2 triệu người cao tuổi, trong đó có 200.000 người được mổ thủy tinh thể miễn phí gần 400 tỉ đồng (Nguyen, 2017). Theo báo cáo tổng quan của ngành y tế số lượng người cao tuổi có thẻ bảo hiểm y tế tăng từ 24,3\% năm 2004 lên 63\% năm 2006, các hoạt động khám sức khỏe định kỳ cho người cao tuổi có thẻ bảo hiểm y tế được thực hiện hiệu quả, chất lượng phục vụ tốt hơn, nhiều địa phương có chủ trương thành lập quỹ chăm sóc sức khỏe người cao tuổi, hoạt động chăm sóc sức khỏe cho người cao tuổi có nhiều điểm mới: chăm sóc tại nhà, chăm sóc tại cơ sở tập trung và chăm sóc dựa vào cộng đồng... (Viện Khoa học xã hội Việt Nam, 2010). Tuy nhiên, việc đảm bảo quyền được chăm sóc sức khỏe cho người cao tuổi thời gian qua cũng đứng trước các thách thức lớn. Thứ nhất, chất lượng các loại dịch vụ y tế, khám chữa bệnh có thẻ bảo hiểm y tế, vấn đề y đức, tiêu cực trong ngànhy tế, ... có tác động tiêu cực đến thực hiện quyền được đảm bảo chăm sóc sức khỏe của người cao tuổi nếu xem đây là lực lượng yếu thế trong xã hội. Thư hai, tỉ lệ người cao tuổi đến khám, chữa bệnh và được lập hồ sơ quản lý sức khỏe định kỳ tại tuyến cơ sở rất thấp, nhiều bệnh viện tuyến huyện chưa thành lập được Khoa lão khoa, công tác cải cách thủ tục hành chính của ngành y tế còn chậm.

\subsubsection{Quyền được đảm bảo các giá trị tinh thần}

Ngoài việc được đảm bảo hỗ trợ, chia sẻ về vật chất, đảm bảo sức khỏe thì người cao tuổi theo Hiến pháp, pháp luật còn có quyền được đảm bảo các giá trị về mặt tinh thần. Điều này thể hiện rõ ở việc người cao tuổi được quyền tham gia, tiếp cận với các loại hình hoạt động văn hóa, văn nghệ, thể dục, thể thao, du lịch, nghỉ mát, các hoạt động khác bồi bổ, nâng cao đời sống tinh thần cho người cao tuổi, sự quan tâm, thăm hỏi, động viên, chúc thọ người cao tuổi,... Tính đến hết năm 2016, cả nước có 58.099 câu lạc bộ người cao tuổi, thu hút 2,6 triệu người cao tuổi tham gia, góp phần nâng cao sức khỏe, tinh thần va bảo tồn bản sắc văn hóa dân tộc 
(Ủy ban quốc gia về người cao tuổi, 2016). Tuy nhiên, hạn chế lớn nhất của các tổ chức này chính là tính hình thức hay hành chính hóa, chưa đem lại lợi ích thiết thực, ý nghĩa, thậm chí mang tính phong trào. Đánh giá việc đảm bảo quyền được chăm lo về đời sống tinh thần, chỉ có $8,6 \%$ người cao tuổi đánh giá nó được thực hiện mức độ tốt, rất tốt; $54,7 \%$ cho rằng chính sách này không được thực hiện tốt ở địa phương (Viện Khoa học xã hội Việt Nam, 2010).

\subsubsection{Quyền được xã hội thì̀ nhận, tôn trọng và khẳng định vị thế}

Phải khẳng định, đây là quyền rất tiến bộ và rất mới của người cao tuổi được Hiến pháp năm 2013 ghi nhận. Có thể thấy, đây vừa là quyền nhưng cũng là nhu cầu tất yếu của người cao tuổi. Quyền này được hiểu chính là việc người cao tuổi với đầy đủ phẩm chất, kỹ năng, năng lực, ... được xã hội coi trọng, ghi nhận và bản thân người cao tuổi sử dụng nó để góp phần tiếp tục cống hiến cho xã hội.

Theo kết quả khảo sát của các cơ quan nghiên cứu cho thấy, có hơn 2,5 triệu người cao tuổi vẫn đang tham gia lao động, sản xuất kinh doanh; 95.000 người cao tuổi làm trang trại, cơ sở sản xuất, kinh doanh; hơn 300.000 nghìn người cao tuổi làm kinh tế giỏi; 1,24 triệu người cao tuổi nghỉ hưu vẫn tham gia công tác trong hệ thống chính trị tại nơi cư trú, ... (Bộ Lao động - Thương binh và Xã hội \& UNFPA, 2014). Ngoài các công việc trên, người cao tuổi còn tạo điều kiện để tham gia vào hoạt đông giáo dục, đào tạo, bồi dưỡng (khuyến học, khuyến tài,...), tham gia thiết chế tự quản cơ sở (khu phố, tổ dân phố, thôn, bản,...), tham gia công tác đảm bảo an ninh trật tự, chống tội phạm, hòa giải cơ sở,... Nhìn tổng thể, chính sách người cao tuổi thông qua việc đảm bảo quyền công dân, quyền con người -người cao tuổi được tham gia, đóng góp, khẳng định giá trị của người cao tuổi được thực hiện khá tốt, góp phần xây dựng và bảo vệ Tổ quốc. Tuy nhiên, việc đảm bảo người cao tuổi tham gia tiếp tục cống hiến, khẳng định giá trị của mình vẫn còn nhiều khiếm khuyết như chưa thu hút được người cao tuổi tham gia hỗ trợ địa phương, sáng kiến của người cao tuổi chưa được coi trọng, tiếp thu, chưa có chiến lược mang tầm quản trị quốc gia về thu hút, sử dụng hợp lí, hiệu quả nguồn nhân lực - người cao tuổi ở nước ta, ... Tất cả hạn chế này tạo nên sự lãng phí lớn nhân lực của xã hội.

\section{Kiến nghị chính sách nhằm củng cố, phát huy quyền con người, quyền công dân - người cao tuổi trong chính sách người cao tuổi theo Hiến pháp Việt Nam}

Thông qua việc phân tích chính sách người cao tuổi từ cách tiếp cận quyền con người, quyền công dân trong Hiến pháp Việt Nam và thực tiễn về cách tiếp cận này, dựa trên các tồn tại, thách thức mà chính sách người cao tuổi đã nhận diện, tác giả đề xuất một số khuyến nghị chính sách. Cụ thể như sau:

Một là, nghiên cứu và có cơ chế, chính sách nhằm khuyến khích sự tham gia của toàn xã hội, huy động nguồn lực của khu vực tư (tăng cường xã hội hóa) trong việc giải quyết các vấn đề lớn trong chính sách người cao tuổi, góp phần đảm bảo khắc phục khó khăn hiện tại ngân sách cho các khoản trợ cấp, phục vụ thiết lập Quỹ người cao tuổi tại các địa phương, mở rộng diện thụ hưởng nhận hỗ trợ vật chất cho người cao tuổi... Đặc biệt, coi trọng phát triển, nhân rộng mô hình tham vấn, hỗ trợ chăm sóc người cao tuổi thông qua vai trò của cộng đồng, xã hội và các tổ chức hành nghề công tác xã hội. 
Hai là, đẩy mạnh cải cách hành chính nhà nước trong lĩnh vực y tế, trong đó, chú trọng đến việc cải cách thủ tục liên quan cung ứng dịch vụ y tế cho người cao tuổi, chấn chỉnh trách nhiệm công vụ, nâng cao y đức của đội ngũ y bác sĩ. Đặc biệt, cần có chiến lược quy hoạch tổng thể ngành y để thích ứng với vấn đề già hóa dân số của Việt Nam hiện nay. Trong đó, cần quan tâm xây dựng nguồn nhân lực ngành y chất lượng, có phẩm chất nhằm đảm bảo cung ứng dịch vụ y tế, hỗ trợ giải quyết các vấn đề phát sinh khi già hóa dân số. Đồng thời, nghiên cứu xây dựng hệ thống cơ sở vật chất kỹ thuật như Viện Lão học, viện dưỡng lão, trung tâm chăm sóc người cao tuổi, ...và trang bị tri thức để cộng đồng và xã hội thích ứng với già hóa dân số một cách tích cực.

Ba là, các nhà hoạch định chính sách cần nghiên cứu, tham vấn để ban hành chiến lược về tận dụng, sử dụng nguồn nhân lực từ đội ngũ người cao tuổi đảm bảo khoa học hợp lí. Như phân tích trên, với tinh thần "tuổi cao chí càng cao", người cao tuổi ngày càng có vai trò quan trọng, trở thành nguồn lực đắc giá trong sự nghiệp xây dựng và bảo vệ Tổ quốc hiện nay. Do vậy, các cơ quan quản lý nhà nước, các nhà hoạch định, tham vấn chính sách người cao tuổi cần đặt chính sách thu hút, sử dụng hiệu quả nguồn lực người cao tuổi trong tổng thể chính sách người cao tuổi ở nước ta.

Bốn là, các cơ quan chức năng, cơ quan truyền thông, và đoàn thể chính trị - xã hội thường xuyên quan tâm đến công tác tuyên truyền, phổ biến về chính sách người cao tuổi của Nhà nước đến đội ngũ người cao tuổi. Việc nhận thức đầy đủ về thách thức già hóa dân số của người dân có tác động tích cực trong việc kéo dài thời gian già hóa dân số, cân bằng cơ cấu dân số quốc gia thông qua chiến lược dân số, kế hoạch hóa gia đình, chăm sóc sức khỏe, ... Bên cạnh đó, cần nhận thức rõ ràng rằng, trong hoạt động của các cơ quan này, cần xem việc chăm lo người cao tuổi cùng toàn xã hội là trách nhiệm, là hành vi đạo đức và gìn giữ truyền thống dân tộc Việt Nam bên cạnh nghĩa vụ pháp lý, trách nhiệm công vụ.

Năm là, tăng cường, mở rộng hợp tác quốc tế trong thực hiện chính sách người cao tuổi và thích ứng với vấn đề già hóa dân số ở nước ta. Việt Nam cần tranh thủ mối quan hệ hợp tác quốc tế với các quốc gia có nhiều kinh nghiệm trong ứng phó chủ động với vấn đề già hóa dân số, thực hiện tốt chính sách người cao tuổi nhằm sẻ chia kiến thức, học tập mô hình, kinh nghiệm và vận dụng sáng tạo, linh hoạt gắn với văn hóa, đặc thù tình hình kinh tế - chính trị của quốc gia. Ngoài ra, cần tăng cường và tranh thủ sự ủng hộ, giúp đỡ trong huy động nguồn lực, kỹ thuật, thực hiện tham vấn chính sách người cao tuổi, ... cho các cơ quan nhà nước nhằm kịp thời điều chỉnh, cập nhật và ứng phó với diễn biến mới của vấn đề già hóa dân số Việt Nam trong tương lai.

\section{Kết luận}

Việc nghiên cứu chính sách người cao tuổi thông qua tiếp cận từ quyền cơ bản của công dân, quyền con người ở góc độ nhận thức lý luận và soi rọi thực tiễn trong các bản Hiến pháp Việt Nam từ khi lập quốc đến nay đã cung cấp một cái nhìn toàn diện, sâu sắc, chân thực về quyền cơ bản của người cao tuổi. Qua phân tích để thấy rằng, chính sách người cao tuổi của nước ta không chỉ dừng lại ở góc độ đạo đức, truyền thống mà còn thể hiện rất rõ ở trong văn kiện chính trị - pháp lý là Hiến pháp. Việc nghiên cứu công phu những nội dung và hình thức thể hiện của chính sách người cao tuổi trong các bản Hiến pháp Việt Nam cùng với đó là thực 
trạng, những kiến nghị chính sách sẽ góp phần cung cấp cứ liệu quan trọng, vững chắc và có sức thuyết phục cao trong nghiên cứu tiếp các nội dung chuyên sâu về chính sách người cao tuổi ở nước ta thời gian tới.

\section{Tài liệu tham khảo}

Bộ Lao động - Thương binh và Xã hội \& UNFPA. (2014). Báo cáo đánh giá: Đánh giá 5 năm thực hiện Luật Người cao tuổi (2010-2014) [Assessment report: Evaluation of 5 years of implementation of the Law on the Elderly (2010-2014)]. Retrieved Octorber 12, 2016, from http://www.molisa.gov.vn/Pages/tintuc/chitiet.aspx?tintucID=21366

Bộ Lao động - Thương binh và Xã hội. (2009). Dư thảo chiến lược an sinh xã hội và chiến lược phát triển day nghề giai đoạn 2011-2020 [Draft strategy for social security and vocational training development for the period 2011-2020]. Retrieved Octorber 12, 2016, from http://www.molisa.gov.vn/Pages/tintuc/chitiet.aspx?TinTucID=213728\&page=53

Nguyen, D. V. (2017). Luật người cao tuổi: Thực tiễn triển khai sau 8 năm ban hành [Law on the elderly: Practical implementation after 8 years of promulgation]. Tạp chí Xã hộ học, 1(137), 66-67.

Pham, T., \& Do, H. T. K. (2009). Báo cáo tổng quan về chính sách chăm sóc người già thích ứng với thay đổi cơ cấu tuổi tại Việt Nam [An overview report on aged care policies adapting to age structure changes in Vietnam]. Hanoi, Vietnam: UNFPA.

Quốc hội. (1946). Hiến pháp năm 1946 [The 1946 Constitution]. Retrieved Octorber 11, 2017, from

https://moj.gov.vn/vbpq/lists/vn\%20bn\%20php\%20lut/view_detail.aspx?itemid=536

Quốc hội. (1959). Hiến pháp năm 1959 [The 1959 Constitution]. Retrieved Octorber 12, 2017, from https://luatminhkhue.vn/hien-phap-nam-1959.aspx

Quốc hội. (1980). Hiến pháp năm 1980 [The 1980 Constitution]. Retrieved Octorber 13, 2017, from https://tulieuvankien.dangcongsan.vn/he-thong-van-ban/van-ban-quy-pham-phapluat/hien-phap-nam-1980-236

Quốc hội. (1992). Hiến pháp năm 1992 [The 1992 Constitution]. Retrieved Octorber 14, 2017, from

https://moj.gov.vn/vbpq/lists/vn\%20bn\%20php\%20lut/view_detail.aspx?itemid=22335

Quốc hội. (2013). Hiến pháp năm 2013 [The 2013 Constitution]. Retrieved Octorber 15, 2017, from https://thuvienphapluat.vn/van-ban/Bo-may-hanh-chinh/Hien-phap-nam-2013215627.aspx

Quỹ dân số Liên Hiệp quốc tại Việt Nam - UNFPA. (2012). Báo cáo tóm tắt: Già hóa trong Thế kỷ 21: Thành tưu và thách thức [Executive summary: Aging in the 21st century: Achievements and challenges]. Retrieved Octorber 20, 2017, from https://www.unfpa.org/sites/default/files/pub-pdf/UNFPA-Exec-Summary_VN.pdf 
Quỹ dân số Liên Hiệp quốc tại Việt Nam - UNFPA. (2015). Thông tin tóm tắt: Đánh giá mô hình thi điểm chăm sóc nguời già dụa vào cộng đồng của Quỹ Dân số Liên Hiệp quốc [Summary: Evaluation of the United Nations Population Fund pilot model of communitybased care for the elderly]. Retrieved Octorber 16, 2017, from https://vietnam.unfpa.org/sites/default/files/pub-

pdf/PD_Summary_assess $\% 20$ piloted $\% 20$ comm\%20based $\% 20$ model $\% 20$ on $\% 20$ care $\% 2$ 0for\%20older\%20people_printed\%20in\%202016_Tieng\%20Viet.pdf

Quỹ dân số Liên Hiệp quốc tại Việt Nam - UNFPA. (2016). Già hóa dân số nhanh chóng ở Việt Nam - Thách thức và co họi [Rapid population aging in Vietnam - Challenges and opportunities]. $\quad$ Retrieved Octorber 17, 2017, from https://vietnam.unfpa.org/vi/publications/gi\%C3\%A0-h\%C3\%B3a-d\%C3\%A2ns\%E1\%BB\%91-nhanh-ch\%C3\%B3ng-\%E1\%BB\%9F-vi\%E1\%BB\%87t-namth\%C3\%A1ch-th\%E1\%BB\%A9c-v\%C3\%A0-c\%C6\%A1-h\%E1\%BB\%99i

Trinh, L. D. (2016). Chính sách chăm sóc người cao tuổi ở Việt Nam hiện nay [Policy on elderly care in Vietnam today]. Tạp chí Khoa học Xã hội Việt Nam, 1(98), 1.

Ủy ban quốc gia về người cao tuổi. (2016). Nghiên cứu đánh giá: Thưc trạng người cao tuổi và tình hình già hóa dân số Việt Nam [Assessment study: The current situation of the elderly and the aging population in Vietnam]. Hanoi, Vietnam: Ủy ban quốc gia về người cao tuổi.

Viện Khoa học xã hội Việt Nam. (2010). Kết quả đề tài nghiên cúu khoa họ: Một số vấn đề co bản về người cao tuổi Việt Nam giai đoạn 2011 - 2020 [Results of scientific research projects: Some basic issues about the elderly in Vietnam in the period 2011 - 2020]. Hanoi, Vietnam: Viện Khoa học xã hội Việt Nam.

Viet Nam Social Work Network. (2010). Tổng quan chính sách của đảng, nhà nước về ngườ cao tuổi [Overview of party and state policies on the elderly]. Hanoi, Vietnam: Viet Nam Social Work Network.

Vu, D. C. (2011). Giáo trình khoa học chính sách [Policy science curriculum]. Hanoi, Vietnam: NXB Đại học Quốc gia Hà Nội. 